Research Article

\title{
Application to Engineering and Medical Data Using Three-Parameter Exponential Model
}

\author{
Waleed Almutiry $\mathbb{D}^{1},{ }^{1}$ Amani Abdullah Alahmadi, ${ }^{2}$ Ibrahim Elbatal, ${ }^{3}$ Ibrahim E. Ragab, ${ }^{4}$ \\ Oluwafemi Samson Balogun $\left(\mathbb{0},{ }^{5}\right.$ and Mohammed Elgarhy $\mathbb{1}^{6}$ \\ ${ }^{1}$ Department of Mathematics, College of Science and Arts, Qassim University, Ar Rass, Saudi Arabia \\ ${ }^{2}$ College of Science and Humanities, Shaqra University, Shaqra, Saudi Arabia \\ ${ }^{3}$ Department of Mathematics and Statistics, College of Science, Imam Mohammad Ibn Saud Islamic University (IMSIU), \\ Riyadh 11432, Saudi Arabia \\ ${ }^{4}$ Higher Institute of Computer, King Mariout, Alexandria 23713, Egypt \\ ${ }^{5}$ School of Computing, University of Eastern Finland, Kuopio 70211, Northern Europe, Finland \\ ${ }^{6}$ The Higher Institute of Commercial Sciences, Al Mahalla Al Kubra, Algarbia 31951, Egypt
}

Correspondence should be addressed to Mohammed Elgarhy; m_elgarhy85@sva.edu.eg

Received 23 September 2021; Accepted 22 October 2021; Published 5 November 2021

Academic Editor: Sikandar Ali

Copyright (c) 2021 Waleed Almutiry et al. This is an open access article distributed under the Creative Commons Attribution License, which permits unrestricted use, distribution, and reproduction in any medium, provided the original work is properly cited.

\begin{abstract}
This paper is devoted to a new lifetime distribution having three parameters by compound the exponential model and the transmuted Topp-Leone-G. The new proposed model is called the transmuted Topp-Leone exponential model; it is useful in lifetime data and reliability. The new model is very flexible; its pdf can be right skewness, unimodal, and decreasing shaped, but the hrf of the suggested model can be unimodal, constant, and decreasing. Numerous statistical characteristics of the new model, notably the quantile function, moments, incomplete moments, conditional moments, mean residual life, mean inactivity time, and entropy are produced and investigated. The system's parameters are estimated using the maximum likelihood approach. All estimators should be theoretically convergent, which is supported by a simulation analysis. Finally, two real-world datasets from the engineering and medical disciplines explore the new model's relevance and adaptability in comparison to the alternatives models such as the beta exponential, the Marshall-Olkin generalized exponential, the exponentiated Weibull, the modified Weibull, and the transmuted Burr type $X$ models.
\end{abstract}

\section{Introduction}

Many experts have offered a wide range of methods for including an extra parameter in distributions, and all these new families have been used to describe data from a wide variety of fields, covering engineering, economics, biological studies, environmental sciences, and so on. These families are created by adding an additional shape parameter to the parent distribution to enhance the capabilities and validity of the data modeling in reality. The statistical literature has demonstrated several new families, the transmuted- $G$ by [1], the logistic- $X$ family by [2], ToppLeone- $G$ (TL-G) by [3], type II half logistic $G$ [4], odd-Burr $G$ by [5], transmuted exponentiated generalized $G$ by [6], Topp-Leone odd Lindley $G$ by [7], odd Frechet $G$ by [8], truncated inverted Kumaraswamy $G$ [9], and truncated Cauchy power $G[10]$, among others.

Reference [11] recently published the TTL-G, a distinct family of continuous distributions with the next distribution function (cdf) and density function (pdf), 


$$
\begin{aligned}
& F(x)=(1+\lambda)\left[1-(1-G(x))^{2}\right]^{\theta}-\lambda\left[1-(1-G(x))^{2}\right]^{2 \theta}, \quad x>0, \theta>0,|\lambda|<1, \\
& f(x)=2 \theta g(x)(1-G(x))\left[1-(1-G(x))^{2}\right]^{\theta-1}\left[1+\lambda-2 \lambda\left\{1-(1-G(x))^{2}\right\}^{\theta}\right]
\end{aligned}
$$

The cdf and pdf corresponding to the $E$ model, respectively, are

$$
\begin{aligned}
& G(x)=1-e^{-\alpha x} ; \quad x>0, \alpha>0, \\
& g(x)=\alpha e^{-\alpha x},
\end{aligned}
$$

where $\alpha$ is the scale parameter. Many authors developed the $E$ model recently like [12-14].

The major goal of this research is to employ the $E$ model as a baseline model in the TTL- $G$ to create a novel extension of the $E$ model called the TTLE model. Inserting equations (3) and (4) in equations (1) and (2), then the cdf and pdf of the proposed model are

$$
\begin{aligned}
F_{\text {TTLE }}(x)= & (1+\lambda)\left(1-e^{-2 \alpha x}\right)^{\theta}-\lambda\left[\left(1-e^{-2 \alpha x}\right)\right]^{2 \theta}, \\
f_{\text {TTLE }}(x)= & 2 \theta \alpha e^{-2 \alpha x}\left(1-e^{-2 \alpha x}\right)^{\theta-1} \\
& \cdot\left[1+\lambda-2 \lambda\left(1-e^{-2 \alpha x}\right)^{\theta}\right] .
\end{aligned}
$$

The random variable (RV) with pdf (6) is now indicated as $X \sim \operatorname{TTLE}(\lambda, \theta, \alpha)$.

Figure 1 demonstrates plots of the pdf of the TTLE model for number of model parameter values. We can note from Figure 1 that the pdf can be decreasing, right skewed, and unimodal shaped.

The remainder of this article is organized as follows: Section 2 focuses on the various new models' statistical characteristics. Section 3 presents reliability measurements such as survival function (sf), hazard rate (hr) function, MREL, and MINT. Section 4 introduces the parameter maximum likelihood estimates by using MATHCAD (14) statistical software. In Section 5, two real-world examples demonstrate the potential and adaptability of the offered model. Results are summarized in Section 6.

\section{Structural Properties}

In this part, we covered the TTLE distribution's characteristics such as the QuF, Mos, Mo generating function, InMos, CMos, MREL, mean inactivity time (MINT), and entropy (EN).
2.1. Quantile Function. The QuF of the TTLE is

$$
Q(u)=F^{-1}(u)=\frac{-1}{2 \alpha} \ln \left\{1-\left[\frac{(1+\lambda)-\sqrt{(1+\lambda)^{2}-4 \lambda u}}{2 \lambda}\right]^{1 / \theta}\right\},
$$

where $u$ is a uniform distribution on $(0,1)$. The Bowley's skewness (BS) measure is dependent on a quantile, see [15], and it is defined by

$$
\mathrm{BS}=\frac{\mathrm{Q}_{0.75}+\mathrm{Q}_{0.25}-2 Q_{0.5}}{\mathrm{Q}_{0.75}-\mathrm{Q}_{0.25}} .
$$

On the other hand, Moors [16] proposed measure of kurtosis $(\mathrm{MK})$ also based on quantiles and it is

$$
\mathrm{MK}=\frac{Q_{0.875}-Q_{0.625}+Q_{0.375}-Q_{0.125}}{Q_{0.75}-Q_{0.25}},
$$

where $Q($.$) represents the QuF. Outliers have less of an$ impact on the measures BS and MK, which exist even for distributions that do not have moments. Figure 2 depicts how BS and MK behave in response to a TTLE distribution. The BS and MK are decreasing from Figure 2.

2.2. Moments. The $r^{\text {th }}$ Mo of TTLE model is computed from

$$
\begin{aligned}
\mu_{r}^{\prime}(x)= & \int_{0}^{\infty} x^{r} f(x) \mathrm{d} x \\
= & 2 \theta \alpha(1+\lambda) \int_{0}^{\infty} x^{r} e^{-2 \alpha x}\left(1-e^{-2 \alpha x}\right)^{\theta-1} \mathrm{~d} x \\
& -4 \lambda \theta \alpha \int_{0}^{\infty} x^{r} e^{-2 \alpha x}\left(1-e^{-2 \alpha x}\right)^{2 \theta-1} \mathrm{~d} x .
\end{aligned}
$$

If $|w|<1$ and $a>0$ is the positive real noninteger, then the binomial series expansion holds.

$$
(1-w)^{b-1}=\sum_{j=0}^{\infty}(-1)^{j}\left(\begin{array}{c}
a-1 \\
j
\end{array}\right) w^{j}
$$

using equation (11), and after some algebraic simplification, the $r^{\text {th }}$ Mo can be expressed as 


$$
\mu_{r}^{\prime}(x)=\sum_{i=0}^{\infty}(-1)^{i} \frac{\theta \Gamma(r+1)}{(2 \alpha)^{r}(i+1)^{r+1}}\left[(1+\lambda)\left(\begin{array}{c}
\theta-1 \\
i
\end{array}\right)-2 \lambda\left(\begin{array}{c}
2 \theta-1 \\
i
\end{array}\right)\right]
$$

Similarly, the Mo generating function of TTLE model can be deduced from equation (6) as follows:

$$
\begin{aligned}
\underset{X}{M}(t)=E\left(e^{t X}\right) & =\int_{0}^{\infty} e^{t x} f(x) \mathrm{d} x \\
& =\sum_{i=0}^{\infty}(-1)^{i} \frac{2 \alpha \theta}{[2 \alpha(i+1)-t]}\left[(1+\lambda)\left(\begin{array}{c}
\theta-1 \\
i
\end{array}\right)-2 \lambda\left(\begin{array}{c}
2 \theta-1 \\
i
\end{array}\right)\right]
\end{aligned}
$$

2.3. Conditional Moments. The $s^{\text {th }}$ upper InMo of TTLE distribution can be computed as

$$
\begin{aligned}
\vartheta_{s}(t) & =E\left(X^{s} \mid X>t\right)=\int_{t}^{\infty} x^{s} f(x) \mathrm{d} x \\
& =\sum_{i=0}^{\infty}(-1)^{i} \frac{\theta \Gamma(s+1,2 \alpha(i+1) t)}{(2 \alpha)^{s}(i+1)^{s+1}}\left[(1+\lambda)\left(\begin{array}{c}
\theta-1 \\
i
\end{array}\right)-2 \lambda\left(\begin{array}{c}
2 \theta-1 \\
i
\end{array}\right)\right],
\end{aligned}
$$

where $\Gamma(s, t)=\int_{t}^{\infty} x^{s-1} e^{-x} \mathrm{~d} x$ is the upper in gamma function. Similarly, the $s^{\text {th }}$ lower InMo of TTLE model is

$$
\begin{aligned}
& \phi_{s}(t)=E\left(X^{s} \mid X<t\right)=\int_{0}^{\infty} x^{s} f(x) \mathrm{d} x \\
& \phi_{s}(t)=\sum_{i=0}^{\infty}(-1)^{i} \frac{\theta \gamma(s+1,2 \alpha(i+1) t)}{(2 \alpha)^{s}(i+1)^{s+1}}\left[(1+\lambda)\left(\begin{array}{c}
\theta-1 \\
i
\end{array}\right)-2 \lambda\left(\begin{array}{c}
2 \theta-1 \\
i
\end{array}\right)\right],
\end{aligned}
$$

where $\gamma(s, t)=\int_{0}^{t} x^{s-1} e^{-x} \mathrm{~d} x$ is the lower in gamma function.

$$
I_{R}(\rho)=\frac{1}{1-\rho} \log \left[\int_{0}^{\infty} f^{\rho}(x) \mathrm{d} x\right], \quad \rho>0, \rho \neq 1,
$$

2.4. Entropy. The Rényi EN is calculated from

Using equation (6), we have

$$
\begin{aligned}
\int_{0}^{\infty} f^{\rho}(x) \mathrm{d} x & =(2 \theta \alpha)^{\rho} \int_{0}^{\infty} e^{-2 \rho \alpha x}\left(1-e^{-2 \alpha x}\right)^{\rho(\theta-1)}\left[1+\lambda-2 \lambda\left(1-e^{-2 \alpha x}\right)^{\theta}\right]^{\rho} d x \\
& =(2 \theta \alpha)^{\rho} \sum_{j, k=0}^{\infty}(-1)^{j+k}\left(\frac{2 \lambda}{1+\lambda}\right)^{j}\left(\begin{array}{c}
\theta(\rho+j)-\rho \\
k
\end{array}\right)\left(\frac{1}{2 \alpha(\rho+k)}\right) .
\end{aligned}
$$




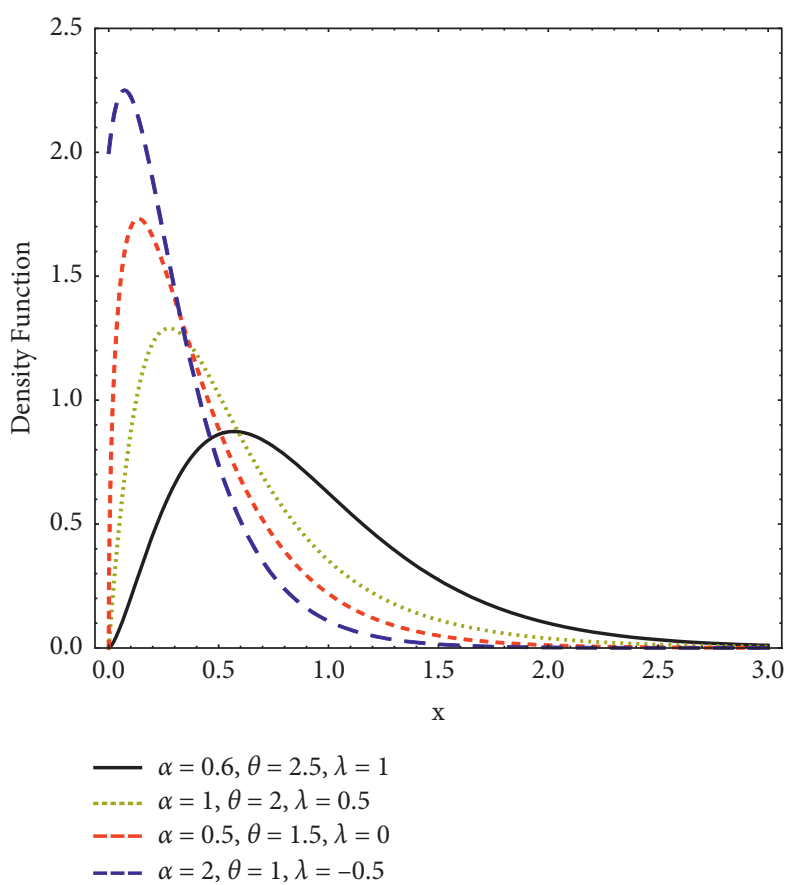

(a)

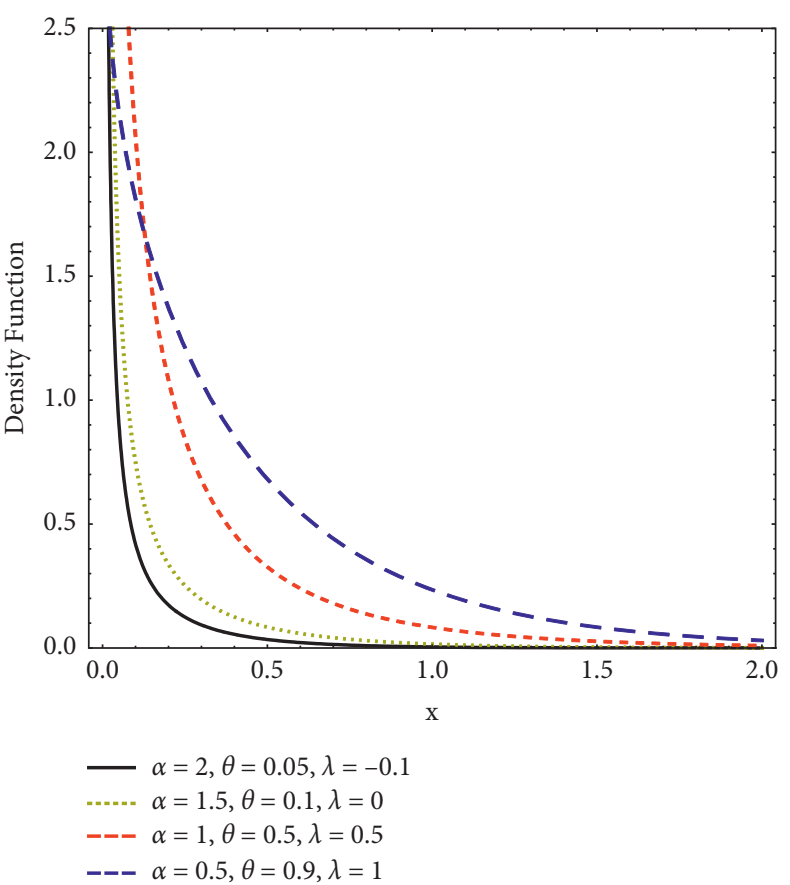

(b)

FIgURE 1: The TTLE pdf shown against various parameter values.

Thus,

$$
I_{R}(\rho)=\frac{\rho}{1-\rho} \log (2 \theta \alpha)+\log \left\{\sum_{j, k=0}^{\infty}(-1)^{j+k}\left(\frac{2 \lambda}{1+\lambda}\right)^{j}\left(\begin{array}{c}
\theta(\rho+j)-\rho \\
k
\end{array}\right)\left(\frac{1}{2 \alpha(\rho+k)}\right)\right\} .
$$

\section{Reliability Measures}

We discussed reliability metrics such as the sf, hr function, MREL, and MINT in this part.

The reliability function (or the sf) of TTLE model is derived by

$$
\bar{F}_{\text {TTLE }}(x)=1-\left(1-e^{-2 \alpha x}\right)^{\theta}\left[(1+\lambda)-\lambda\left(1-e^{-2 \alpha x}\right)^{\theta}\right] .
$$

The hr (or failure rate) function represents the time it takes for a unit to fail or component or a device. It is useful in important measures of ageing.

For the purposes of distribution, the hr function is deduced as follows:

$$
h_{T T L E}(x)=\frac{f(x)}{\bar{F}(x)}=\frac{2 \theta \alpha e^{-2 \alpha x}\left(1-e^{-2 \alpha x}\right)^{\theta-1}\left[1+\lambda-2 \lambda\left(1-e^{-2 \alpha x}\right)^{\theta}\right]}{1-\left(1-e^{-2 \alpha x}\right)^{\theta}\left[(1+\lambda)-\lambda\left(1-e^{-2 \alpha x}\right)^{\theta}\right]} .
$$

Figure 3 illustrates the shapes of sf and hr functions for various values of the distribution parameters. The sf of the TTLE distribution is constantly decreasing, as shown in Figure 3(a). On the other hand, this distribution has the unimodal, constant, and decreasing hr shapes (Figure $3(\mathrm{~b}))$. 


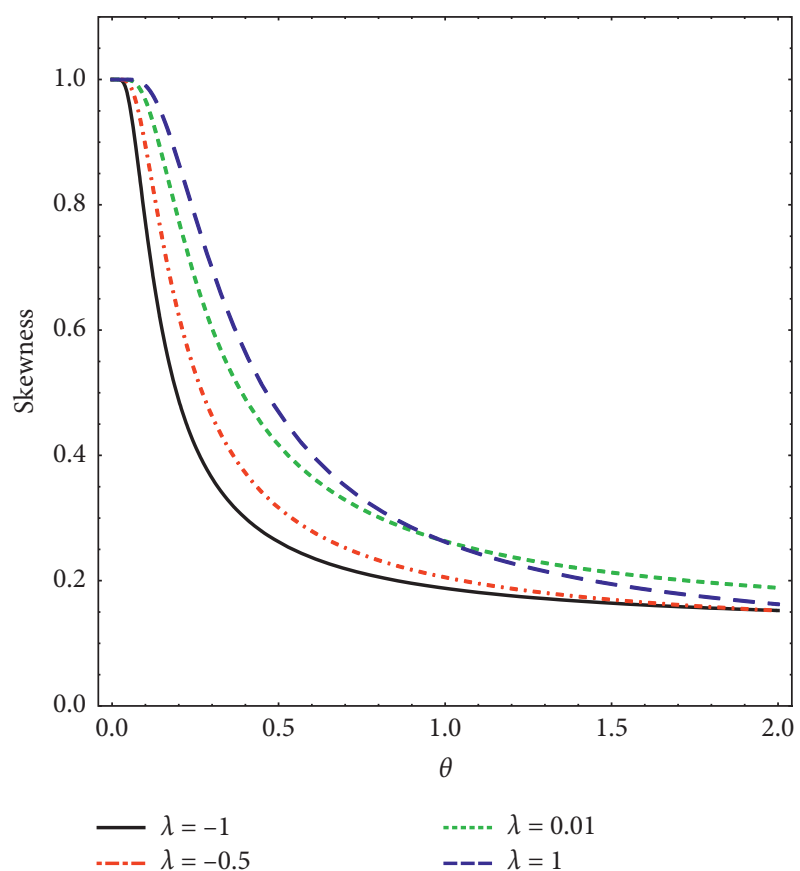

(a)

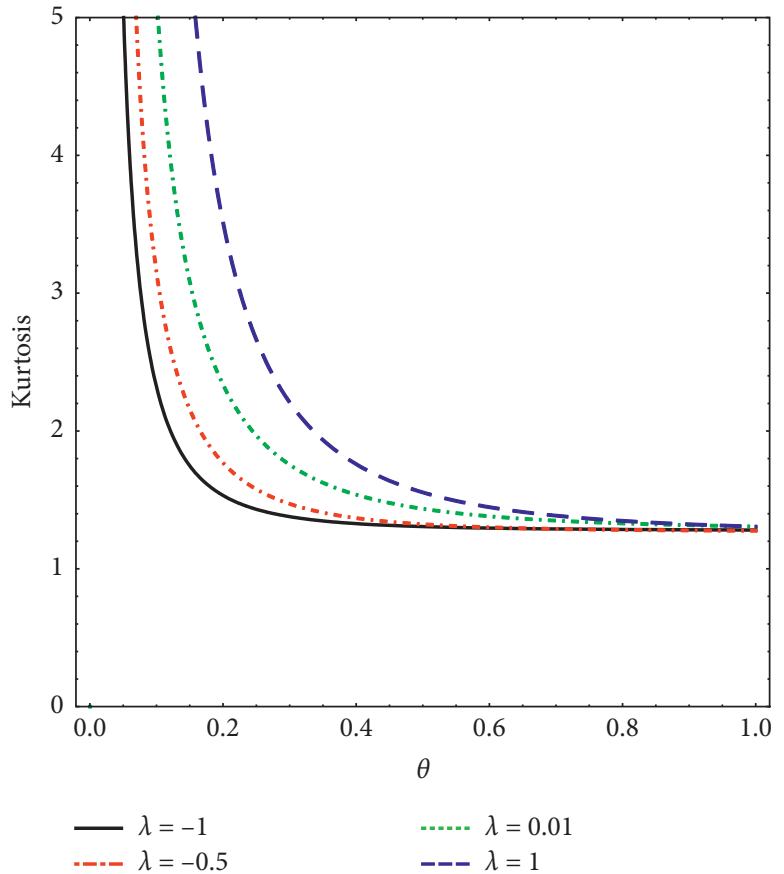

(b)

FIgURE 2: The BS and MK of TTLE distribution.

In the estimation of a sf for left-censored lifetimes, the reversed hr (Rhr) function is crucial. The TTLE distribution's Rhr is calculated by

$$
\tau_{\text {TTLE }}(x)=\frac{f(x)}{F(x)}=\frac{2 \theta \alpha e^{-2 \alpha x}\left[1+\lambda-2 \lambda\left(1-e^{-2 \alpha x}\right)^{\theta}\right]}{\left(1-e^{-2 \alpha x}\right)\left[(1+\lambda)-\lambda\left(1-e^{-2 \alpha x}\right)^{\theta}\right]} .
$$

The MREL function is essential in reliability survival analysis and it is used to model the burn-in and conservation of the component. MREL for TTLE distribution is

$$
\mu(t)=E((X-t) \mid X>t)=\frac{1}{\bar{F}(t)} \int_{t}^{\infty} x f(x) \mathrm{d} x-t .
$$

Then,

$$
\mu(t)=\frac{1}{\bar{F}(t)}(-1)^{i} \frac{\theta \Gamma(2,2 \alpha(i+1) t)}{(2 \alpha)^{2}(i+1)^{2}}\left[(1+\lambda)\left(\begin{array}{c}
\theta-1 \\
i
\end{array}\right)-2 \lambda\left(\begin{array}{c}
2 \theta-1 \\
i
\end{array}\right)\right]-t .
$$

The MINT function is also exciting because it indicates the time that has passed since a component failed, assuming that its lifespan is less than or equal to $t$. That RV is indeed referred to as the time since failure. The MINT is symbolized with

$$
\begin{aligned}
m(t) & =E((X-t) \mid X<t)=t-\frac{1}{F(t)} \int_{0}^{t} x f(x) \mathrm{d} x \\
& =t-\frac{1}{F(t)} \sum_{i=0}^{\infty}(-1) \frac{\theta \gamma(2,2 \alpha(i+1) t)}{(2 \alpha)^{2}(i+1)^{2}}\left[(1+\lambda)\left(\begin{array}{c}
\theta-1 \\
i
\end{array}\right)-2 \lambda\left(\begin{array}{c}
2 \theta-1 \\
i
\end{array}\right)\right] .
\end{aligned}
$$




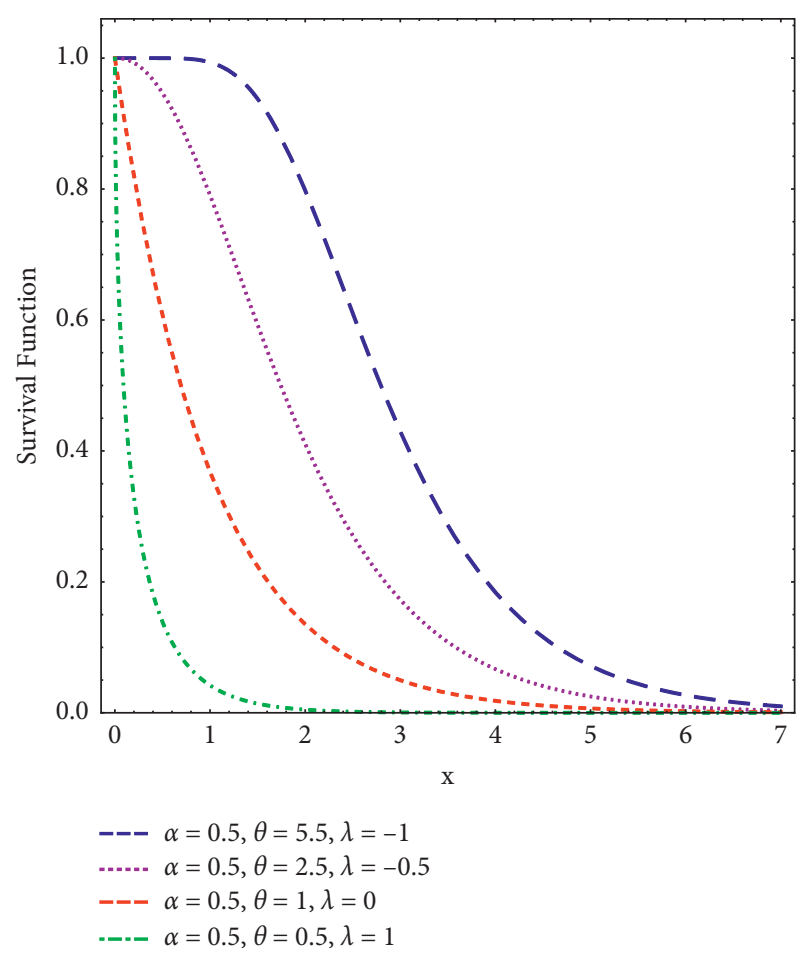

(a)

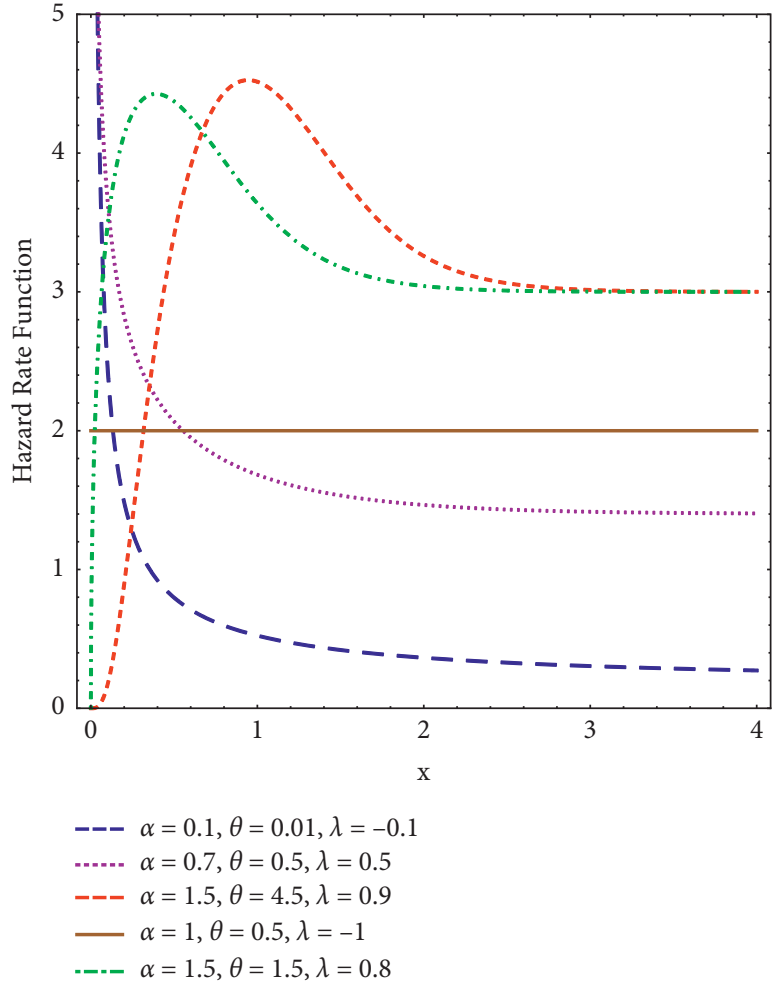

(b)

Figure 3: (a) Plots of TTLE sf. (b) Plots of TTLE hr function.

Table 1 displays the MREL and the MINT for the proposed model at the point $t=0.5$ for some selected values of distribution parameters $(\theta, \lambda)$, namely, $(5.5,-1),(2.5,-0.5)$, $(1,0),(0.5,0.5)$, and $(0.01,1)$, with fixed parameter $\alpha=2$. It is observed that the MREL is decreasing and the MINT is increasing when $\theta$ decreases and $\lambda$ increases.

Figure 4 illustrates the behavior of the MREL and MINT for some different levels of distribution parameters. It is seen that the MREL (Figure 4(a)) is decreasing while the MINT (Figure $4(\mathrm{~b})$ ) is increasing.

\section{Maximum Likelihood Estimation}

MLL estimates (MLLEs) were used to estimate the TTLE distribution's unknown parameters. Suppose $x_{1}, x_{2}, \ldots, x_{n}$ be an $n$-th random sample from the TTLE distribution given by equation (6). The TTLE distribution's log-likelihood formula is represented by

$$
L_{n}=n \log (2 \theta)+n \log (\alpha)-2 \alpha \sum_{i=1}^{n} x_{i}+(\theta-1) \sum_{i=1}^{n} \log \left(1-e^{-2 \alpha x}\right)+\sum_{i=1}^{n} \log \left[1+\lambda-2 \lambda\left(1-e^{-2 \alpha x}\right)^{\theta}\right] .
$$

The likelihood equations for the TTLE distribution can indeed be managed to obtain by differentiating equation (25) with respect to the parameters $\lambda, \theta$, and $\alpha$ which are offered by

$$
\begin{aligned}
& \frac{\partial L_{n}}{\partial \lambda}=\sum_{i=1}^{n} \frac{1-2\left(1-e^{-2 \alpha x}\right)^{\theta}}{1+\lambda-2 \lambda\left(1-e^{-2 \alpha x}\right)^{\theta}}, \\
& \frac{\partial L_{n}}{\partial \theta}=\frac{n}{\theta}+\sum_{i=1}^{n} \log \left(1-e^{-2 \alpha x}\right)+\sum_{i=1}^{n} \frac{-2 \lambda \log \left(1-e^{-2 \alpha x}\right)\left(1-e^{-2 \alpha x}\right)^{\theta}}{1+\lambda-2 \lambda\left(1-e^{-2 \alpha x}\right)^{\theta}},
\end{aligned}
$$


TABle 1: The MREL and MINT of TTLE distribution.

\begin{tabular}{lcccc}
\hline$\theta \downarrow$ & $\lambda \uparrow$ & $\alpha=2, t=0.5$ & MREL $\downarrow$ & \\
\hline 5.5 & -1 & & 0.343799 & \\
2.5 & -0.5 & & 0.278279 & 0.095978 \\
1 & 0 & & 0.250000 & 0.201663 \\
0.5 & 0.5 & 0.237418 & 0.328259 \\
0.01 & 1 & 0.119110 & 0.419510 \\
\hline
\end{tabular}

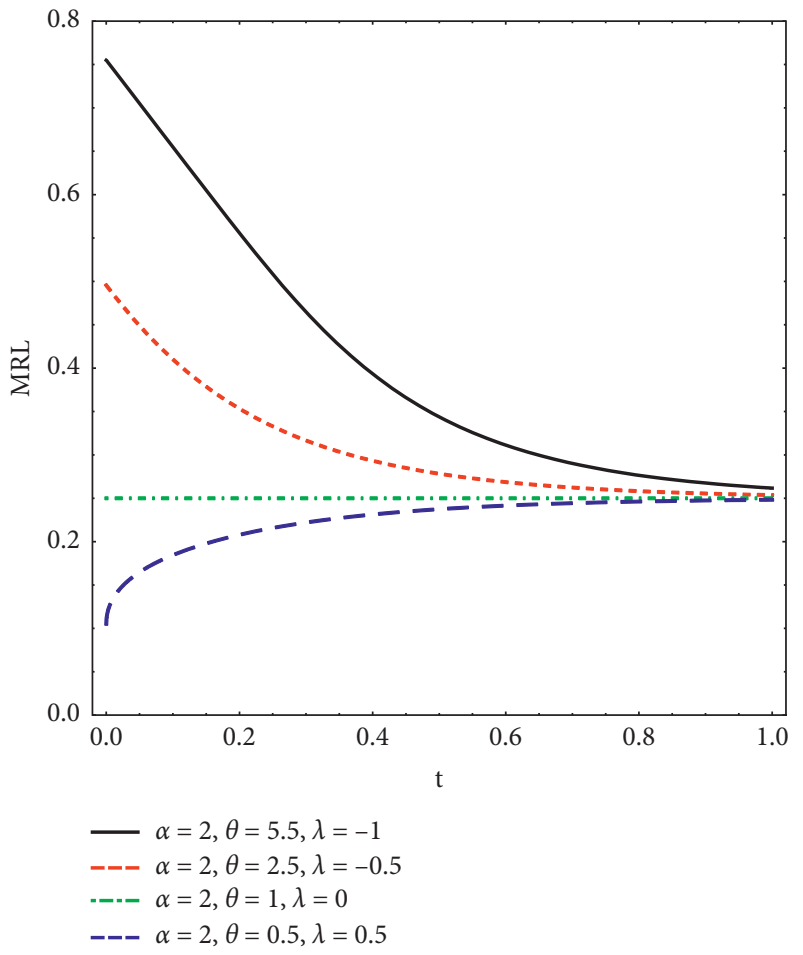

(a)

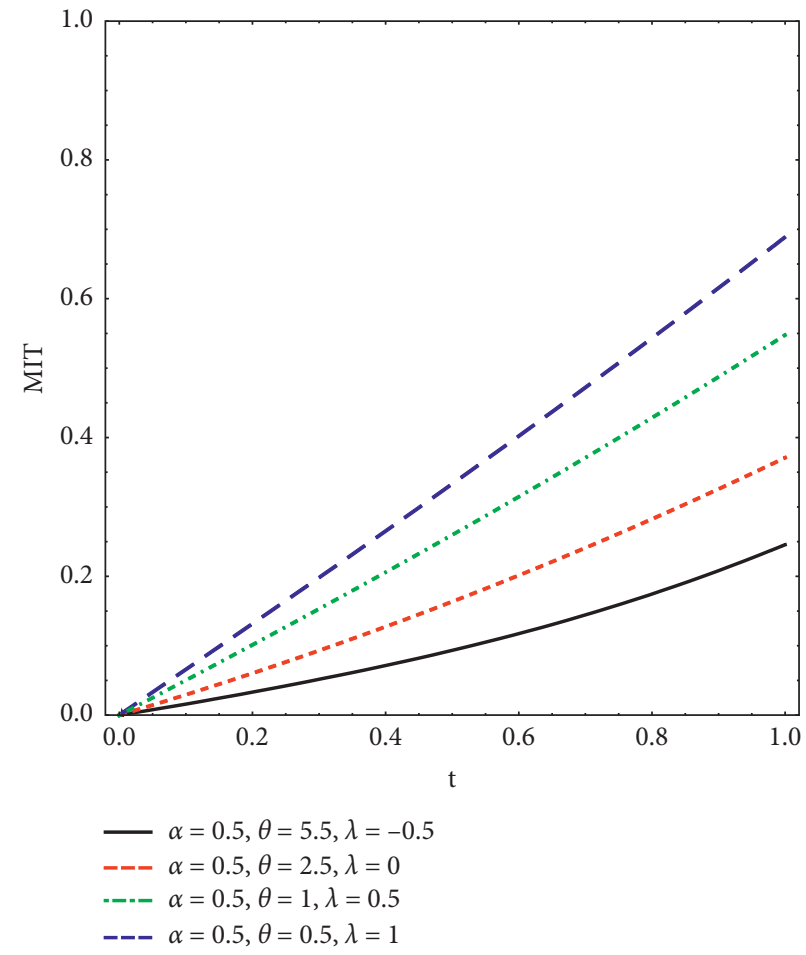

(b)

Figure 4: (a) Plot of MREL and (b) plot of MINT for selected parameter values.

$$
\frac{\partial L_{n}}{\partial \alpha}=\frac{n}{\alpha}-2 \sum_{i=1}^{n} x_{i}+(\theta-1) \sum_{i=1}^{n} \frac{2 x e^{-2 \alpha x}}{\left(1-e^{-2 \alpha x}\right)}-\sum_{i=1}^{n} \frac{4 \lambda \theta x e^{-2 \alpha x}\left(1-e^{-2 \alpha x}\right)^{\theta-1}}{1+\lambda-2 \lambda\left(1-e^{-2 \alpha x}\right)^{\theta}}
$$

The MLEs, say $\hat{\lambda}, \hat{\theta}$, and $\hat{\alpha}$ of parameters $\lambda, \theta$, and $\alpha$, can be acquired by trying to equate and finding solutions of the nonlinear system equations (26)-(28) instantaneously.

4.1. Simulation Results. The output of the MLLEs of the parameters of the TTLE distribution is analyzed through Monte-Carlo simulation inside this subsection. The high accuracy of MLEs is explored utilizing bias and mean square errors (MSEs). This study is evaluated based on 1000 replicates. Different samples of sizes $25,50,75$, and 100 are generated by using equation (7). The parametric values are considered to be $\lambda=0.5, \theta=1$, and $\alpha=2$. The average MSEs and the average bias of the simulated estimates $\widehat{\varepsilon}_{i}$ can be computed by the following equations:

$$
\begin{aligned}
& \operatorname{MSE}_{\varepsilon}(n)=\frac{1}{N} \sum_{i=1}^{N}\left(\widehat{\varepsilon}_{i}-\varepsilon\right)^{2}, \\
& \operatorname{Bias}_{\varepsilon}(n)=\frac{1}{N} \sum_{i=1}^{N}\left|\widehat{\varepsilon}_{i}-\varepsilon\right|,
\end{aligned}
$$

where $\varepsilon=(\lambda, \theta, \alpha)$. 
TABLE 2: Simulation results for TTLE distribution.

\begin{tabular}{|c|c|c|c|c|}
\hline & $n=25$ & $n=50$ & $n=75$ & $n=100$ \\
\hline \multicolumn{5}{|l|}{$\alpha=2$} \\
\hline$\widehat{\alpha}$ & 2.0936 & 2.01643 & 2.00074 & 1.96012 \\
\hline MSE & 0.41260 & 0.2657 & 0.20158 & 0.14632 \\
\hline Bias & 0.09360 & 0.01643 & 0.00074 & 0.0399 \\
\hline \multicolumn{5}{|l|}{$\theta=1$} \\
\hline$\theta$ & 1.07447 & 1.0200 & 1.01687 & 1.00593 \\
\hline MSE & 0.07374 & 0.03027 & 0.01832 & 0.01483 \\
\hline Bias & 0.07447 & 0.01998 & 0.01687 & 0.00593 \\
\hline \multicolumn{5}{|l|}{$\lambda=0.5$} \\
\hline$\lambda$ & 0.52932 & 0.52916 & 0.52839 & 0.52754 \\
\hline MSE & 0.07073 & 0.06495 & 0.05926 & 0.04992 \\
\hline Bias & 0.02932 & 0.02916 & 0.02839 & 0.02754 \\
\hline
\end{tabular}

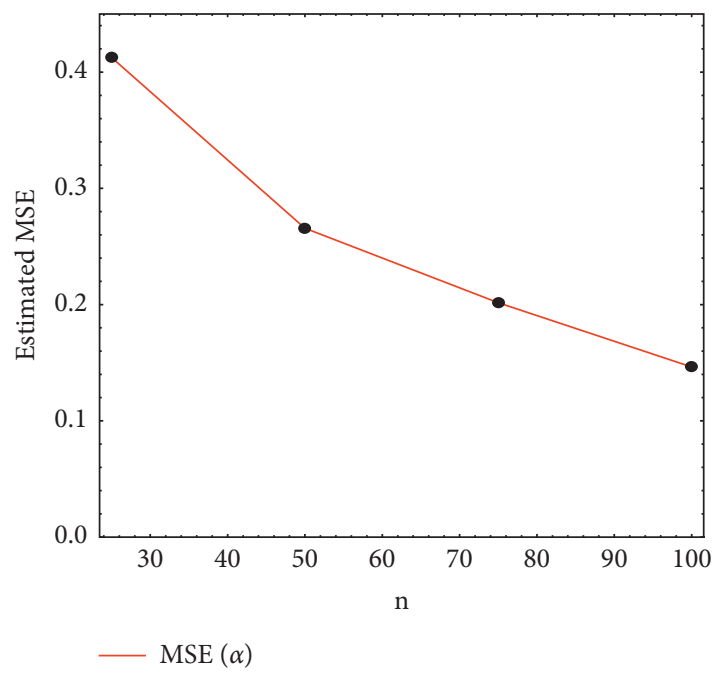

(a)

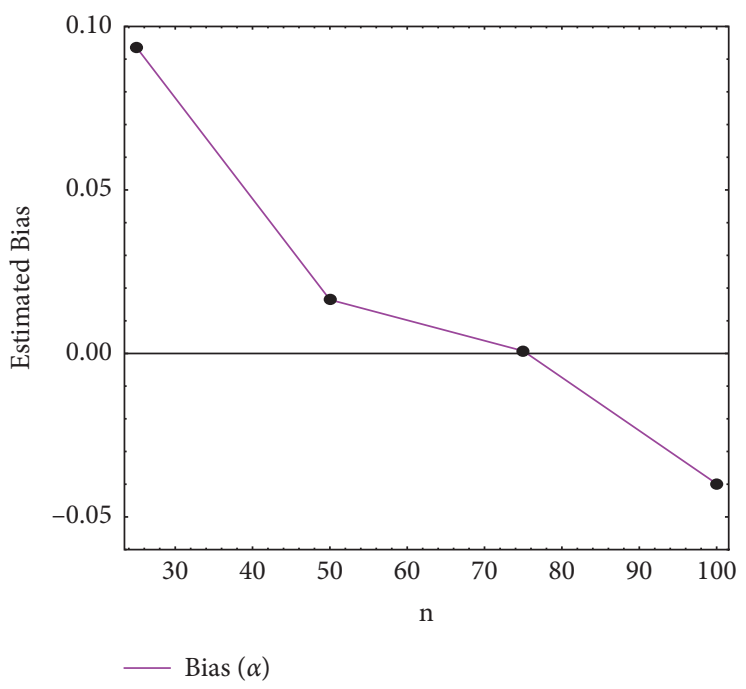

(b)

FIgURE 5: The MSE and bias term of parameter $\alpha$.

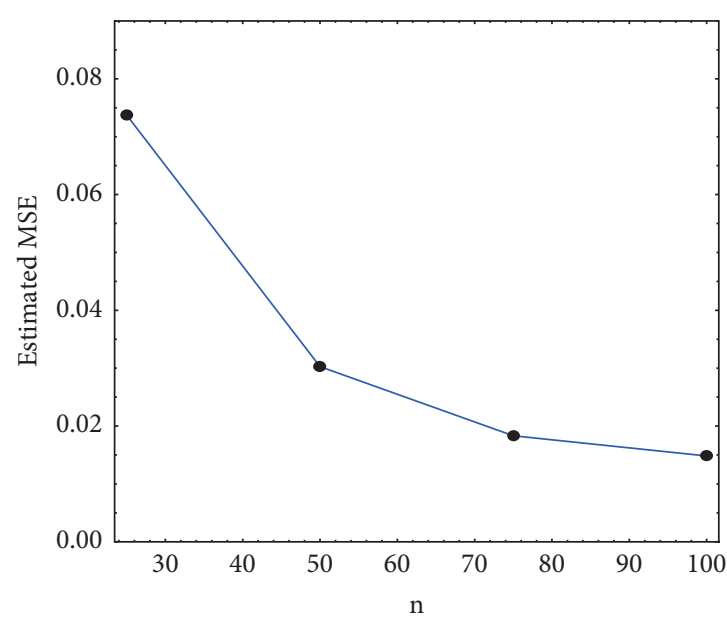

- $\operatorname{MSE}(\theta)$

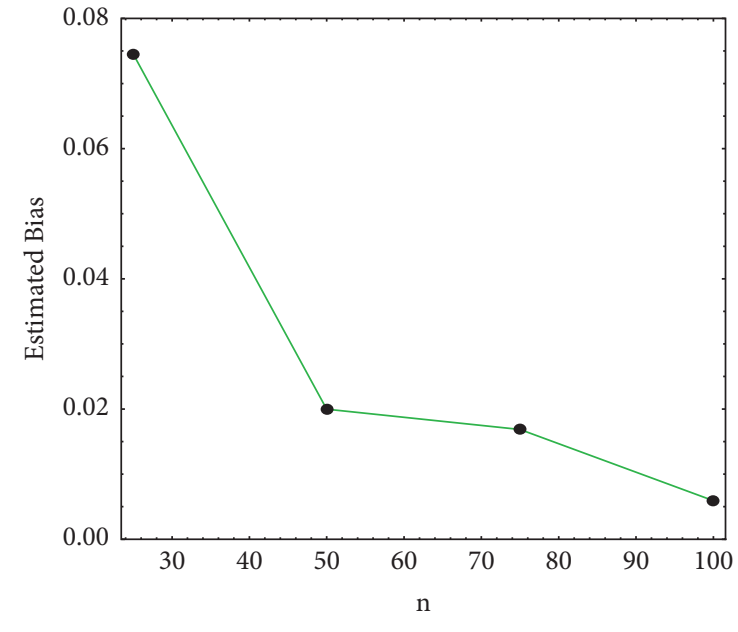

$-\operatorname{Bias}(\theta)$

(a)

Figure 6: The MSE and bias term of parameter $\theta$. 


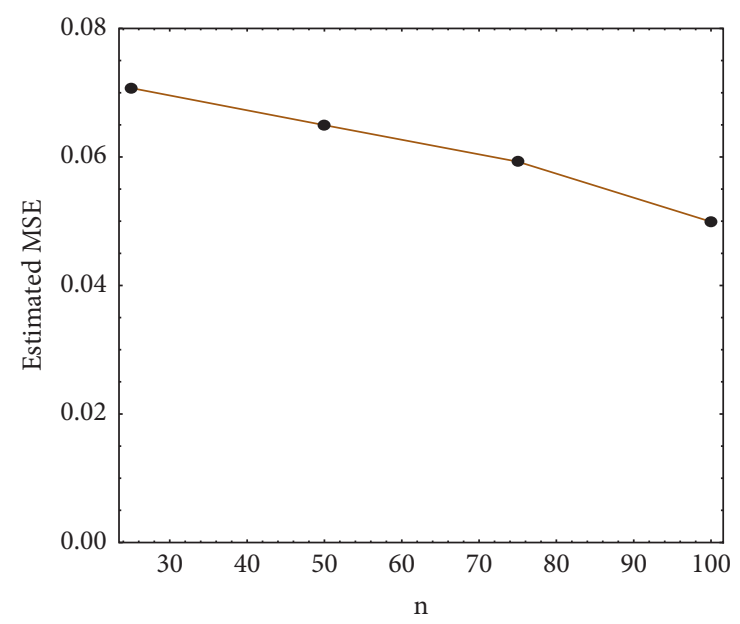

- MSE $(\lambda)$

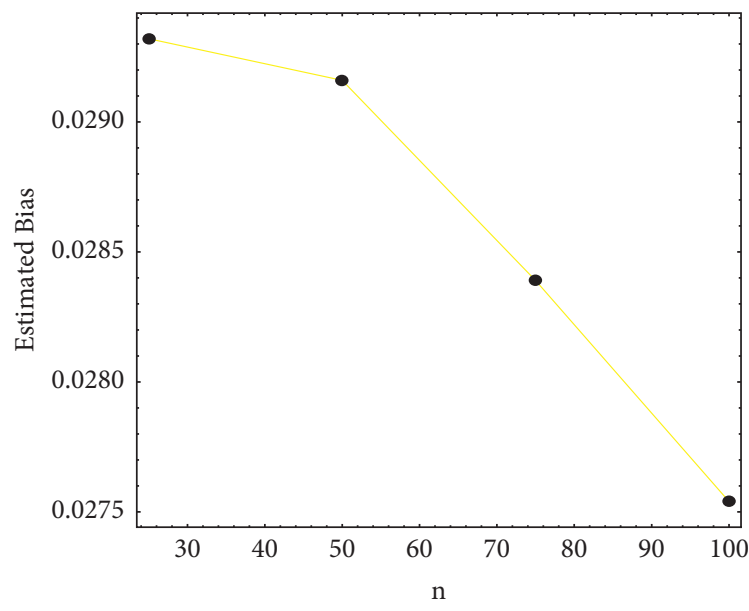

$\operatorname{Bias}(\lambda)$

(a)

Figure 7: The MSE and bias term of parameter $\lambda$.

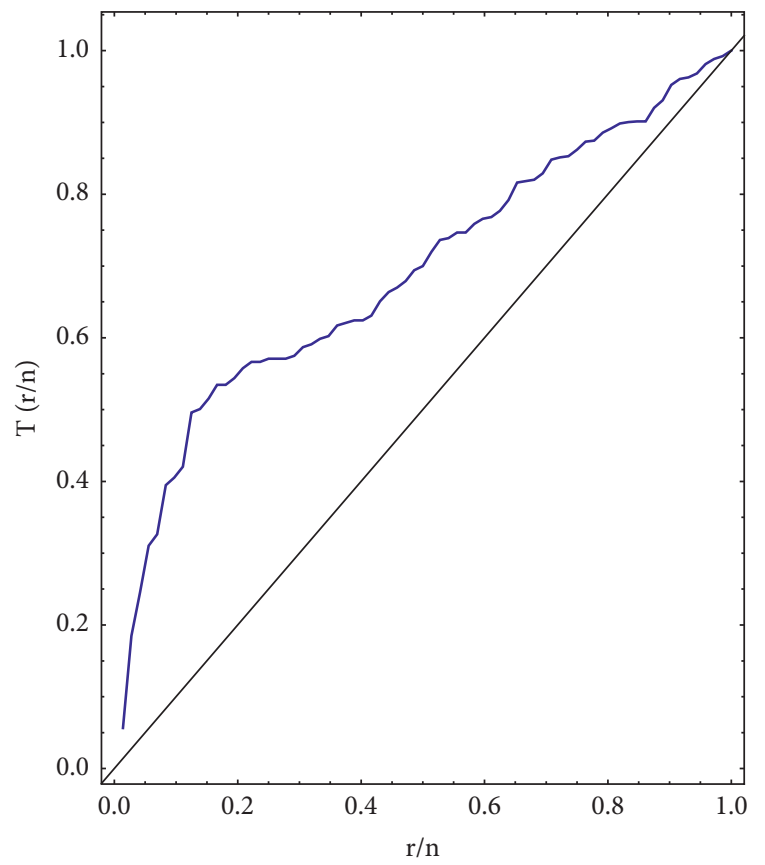

(a)

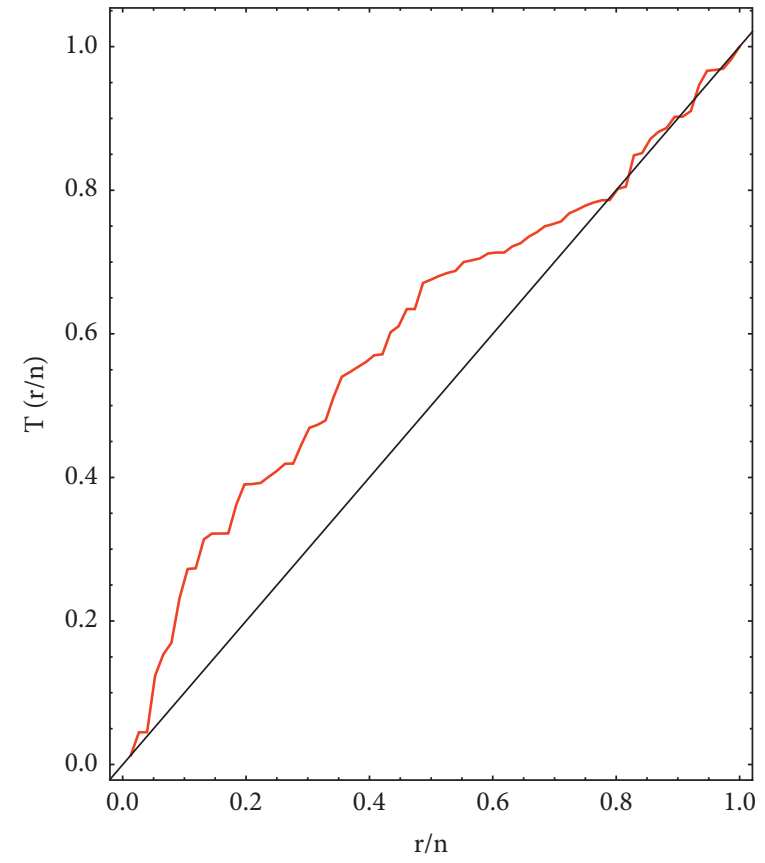

(b)

Figure 8: The TTT plots for (a) Guinea Pig data and (b) Kevlar data.

The estimated values of the distribution parameters, the MSEs, and the bias terms of the simulated estimates are listed in Table 2.

The graphical representations of the simulation process are displayed in Figures 5-7. The following conclusions can be drawn from these figures: when the sample size is increased, the MSEs and estimated biases decrease. Furthermore, for large samples, the approximated values of the parameters approach the parametric values.

\section{Applications}

Within this section, the practical use of the TTLE distribution is explored via two sources of data. The first set of data (Guinea Pig data) was published by [17], while the second set of data (Kevlar data) has been presented by [18].

Reference [19] demonstrated that the TTT plot is convex (or concave) for decreasing (or increasing) failure rate and straight diagonal for constant failure rate. The empirical 
TABle 3: The MLLEs and StErs for the Guinea Pig data.

\begin{tabular}{|c|c|c|c|}
\hline Models & & Estimates & \\
\hline TTLE & $\lambda=-0.83494(0.2045)$ & $\widehat{\theta}=2.38752(0.691)$ & $\widehat{\alpha}=0.00607(0.0007)$ \\
\hline $\mathrm{BE}$ & $\widehat{a}=3.34584(0.964)$ & $\underline{b}=1.70820(3.386)$ & $\widehat{\alpha}=0.00737(0.0119)$ \\
\hline MoGE & $\bar{\delta}=1.03273(1.217)$ & $\bar{\theta}=3.60839(1.0456)$ & $\widehat{\alpha}=0.01136(0.0036)$ \\
\hline EW & $\widehat{\theta}=2.65358(1.53599)$ & $\widehat{\beta}=1.16045(0.30896)$ & $\widehat{\alpha}=0.00886(0.0036)$ \\
\hline MW & $\bar{\eta}=5.86338 \times 10^{-13}(0.0019)$ & $\bar{\delta}=6.32978 \times 10^{-5}(0.00009)$ & $\widehat{\alpha}=1.82535(0.224648)$ \\
\hline TBX & $\widehat{\lambda}=0.63259(0.272)$ & $\widehat{\mu}=1.03896(0.147)$ & $\widehat{\alpha}=0.00417(0.0006)$ \\
\hline
\end{tabular}

TABLE 4: The values of AINC, BINC, and HQINC for the Guinea Pig data.

\begin{tabular}{lccr}
\hline Models & AINC & BINC & HQINC \\
\hline TTLE & 855.805 & 862.635 & 858.524 \\
BE & 857.479 & 864.309 & 860.198 \\
MoGE & 857.616 & 864.446 & 860.335 \\
EW & 857.312 & 864.142 & 860.031 \\
MW & 860.724 & 867.554 & 863.443 \\
TBX & 858.575 & 865.405 & 861.294 \\
\hline
\end{tabular}

Table 5: The values of AND, CVM, A1, and A2 for Guinea Pig data.

\begin{tabular}{lcccc}
\hline Models & AND & CVM & A1 & A2 \\
\hline TTLE & 0.46117 & 0.07596 & 0.07854 & 0.76609 \\
BE & 0.53583 & 0.08439 & 0.09096 & 0.59054 \\
MoGE & 0.52015 & 0.08021 & 0.09312 & 0.56021 \\
EW & 0.54409 & 0.08689 & 0.08912 & 0.616723 \\
MW & 1.01808 & 0.16916 & 0.10479 & 0.40789 \\
TBX & 0.77854 & 0.13183 & 0.08577 & 0.664677 \\
\hline
\end{tabular}

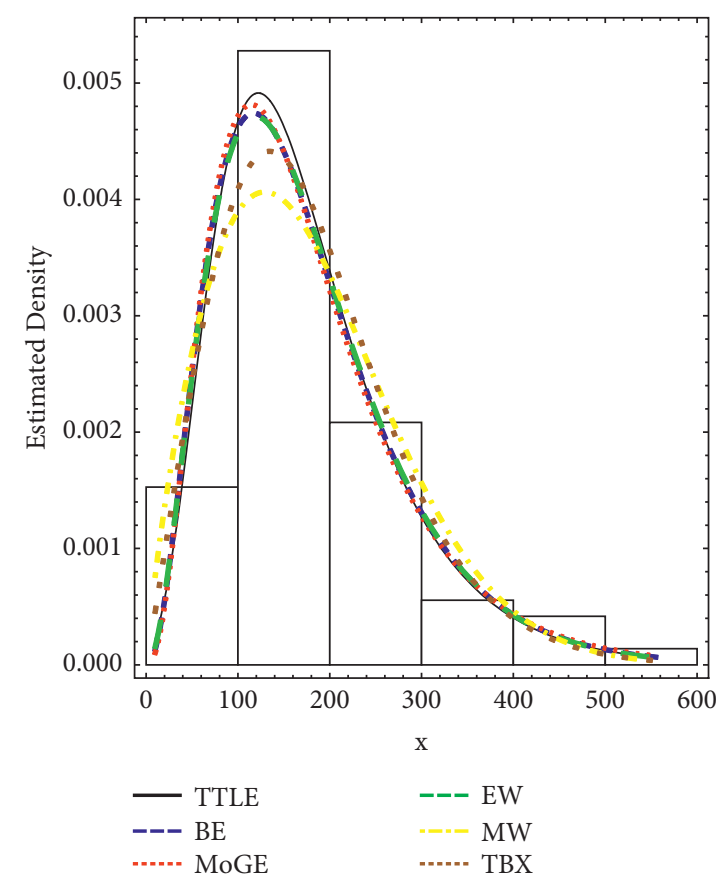

(a)

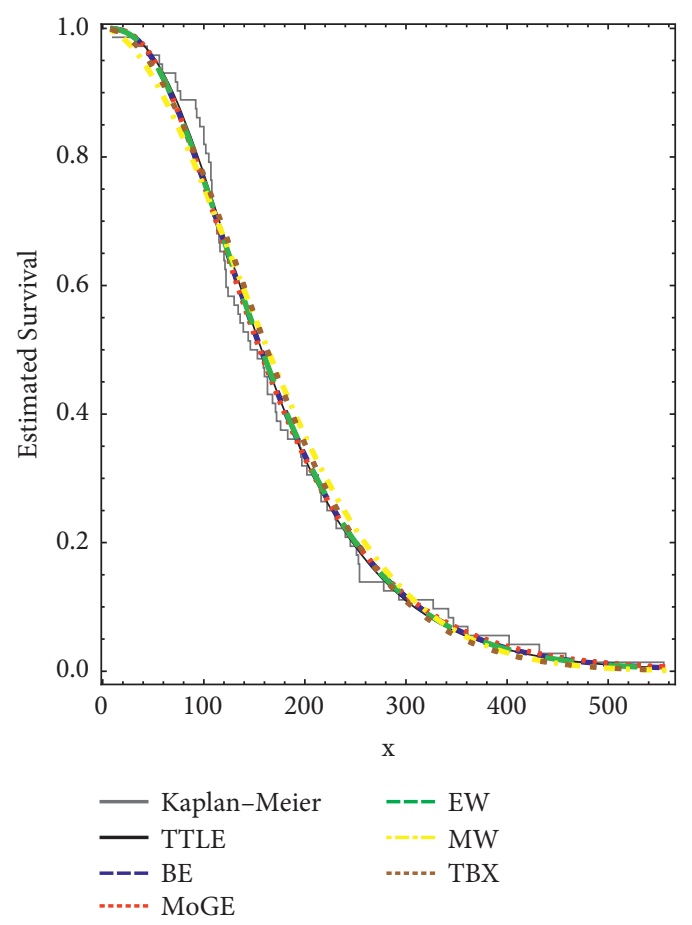

(b)

Figure 9: (a) Estimated density and (b) estimated survival for the Guinea Pig data. 

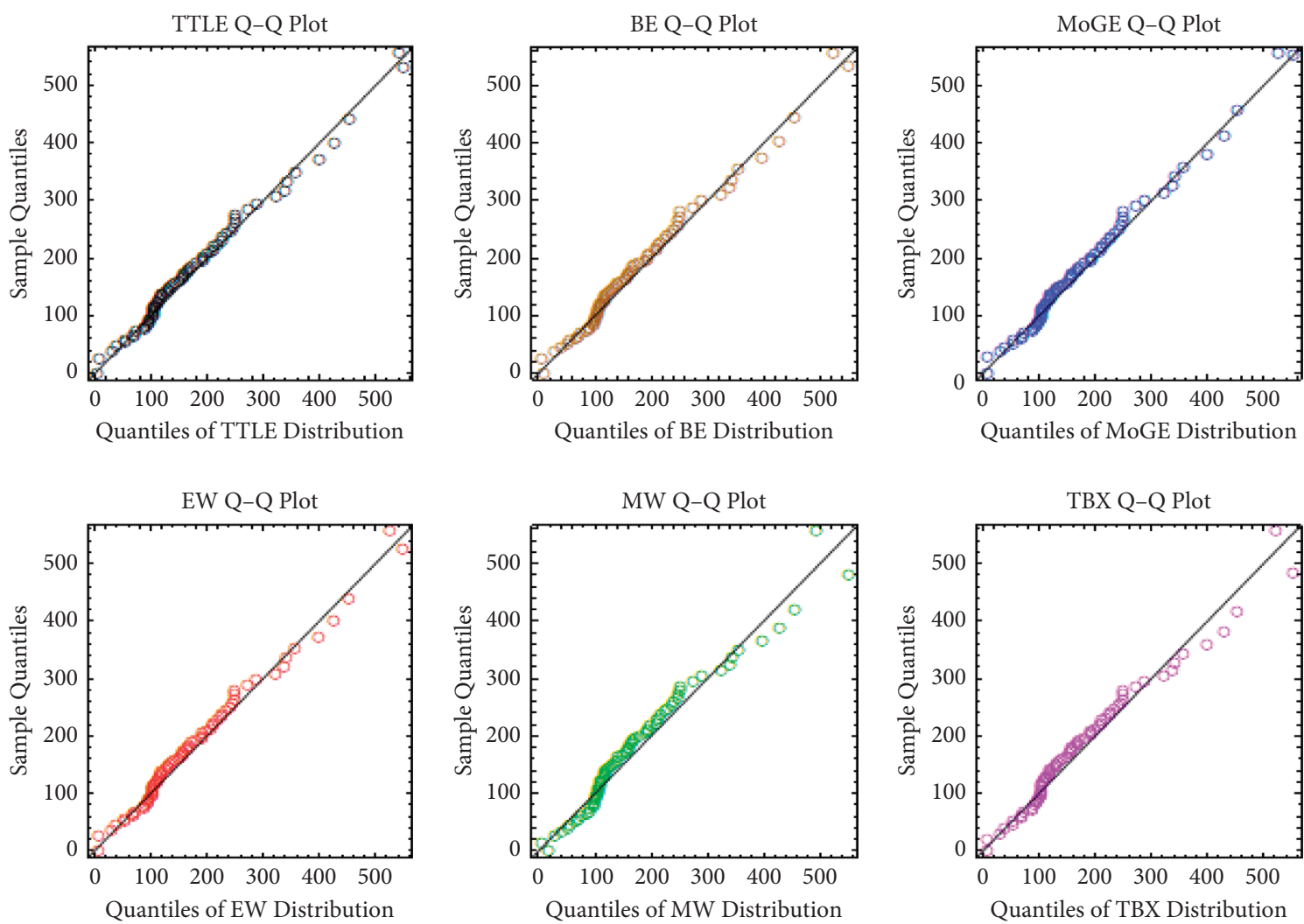

Figure 10: The Q-Q plot of the fitted distributions for the Guinea Pig data.

TABle 6: The MLLEs and StErs for the Kevlar data.

\begin{tabular}{|c|c|c|c|}
\hline Models & & MLLEs and & \\
\hline TTLE & $\begin{array}{c}\lambda=0.84235 \\
(0.34102)\end{array}$ & $\begin{array}{l}\theta=1.70158 \\
(0.30981)\end{array}$ & $\begin{array}{c}\hat{\alpha}=0.22912 \\
(0.07342)\end{array}$ \\
\hline $\mathrm{BE}$ & $\begin{array}{c}a=1.67972 \\
(0.31737)\end{array}$ & $\begin{array}{l}\widehat{b}=1.50842 \\
(4.53703)\end{array}$ & $\begin{array}{c}\widehat{\alpha}=0.48496 \\
(1.32951)\end{array}$ \\
\hline MoGE & $\begin{array}{c}\delta=1.77828 \\
(1.46381)\end{array}$ & $\begin{array}{l}\hat{\theta}=1.44242 \\
(0.49195)\end{array}$ & $\begin{array}{c}\widehat{\alpha}=0.82161 \\
(0.00362)\end{array}$ \\
\hline EW & $\begin{array}{c}\theta=1.44263 \\
(0.64364)\end{array}$ & $\begin{array}{l}\widehat{\beta}=1.10131 \\
(0.26291)\end{array}$ & $\begin{array}{c}\hat{\alpha}=0.60944 \\
(0.21806)\end{array}$ \\
\hline MW & $\begin{array}{c}\eta=0.36638 \\
(0.33046)\end{array}$ & $\begin{array}{c}\widehat{\delta}=1.32561 \\
(0.26353)\end{array}$ & $\begin{aligned} \widehat{\alpha}= & 3.69082 \times 10^{-9} \\
& (0.32066)\end{aligned}$ \\
\hline TBX & $\begin{array}{c}\lambda=0.75459 \\
(0.21087)\end{array}$ & $\begin{array}{c}\widehat{\mu}=0.62374 \\
(0.07648)\end{array}$ & $\begin{array}{c}\alpha=0.25985 \\
(0.03859)\end{array}$ \\
\hline
\end{tabular}

failure rate of the data becomes bathtub-shaped if the TTT plot is convex and then concave; otherwise, the failure rate is upside-down bathtub-shaped.

The scaled TTT plot for every dataset is shown in Figure 8, and it is evident that both sets of data have quite a concave shape, which is indicated that the empirical failure rate of these two datasets is increasing; as a result, the TTLE distribution may be a suitable model for both these datasets. The TTLE distribution is shown to be adaptable using these two examples. The recommended model's goodness-of-fit indicators are compared to the fits of the relevant lifetime models: the BE by [20], the MOGE by [21], the EW by [22], the MW by [23], and the TBX by [24].
We used the MLL technique to estimate the parameters of every model with every set of data. We computed the values of the following information criterion (INC) focusing on the estimations of the unknown parameters: Akaike INC (AINC), Bayesian INC (BINC), and Hannan-Quinn INC (HQINC). The Anderson-Darling (AND), the Cramer-von Mises (CVM) tests, and the Kolmogorov-Smirnov (A1) statistic, as well as the accompanying probability value, are also included (A2). Generally, the optimal model for fitting the data is one with lower values of these measures and a higher $A 2$ of the A1 statistic. Furthermore, for all fitted models, the estimated pdf, estimated sf, and Q-Q plot of the fitted models are taken into account. 
TABLE 7: The values of AINC, BINC, and HQINC for the Kevlar data.

\begin{tabular}{lccc}
\hline Models & AINC & BINC & HQINC \\
\hline TTLE & 249.867 & 256.859 & 252.661 \\
BE & 250.455 & 257.447 & 253.25 \\
MoGE & 250.027 & 257.019 & 252.821 \\
EW & 250.327 & 257.319 & 253.122 \\
MW & 251.049 & 258.042 & 253.844 \\
TBX & 251.669 & 258.661 & 254.463 \\
\hline
\end{tabular}

TABle 8: The values of AND, CVM, A1, and A2 for the Kevlar data.

\begin{tabular}{lcccc}
\hline Models & AND & CVM & A1 & A2 \\
\hline TTLE & 0.593897 & 0.0976829 & 0.0864138 & 0.621551 \\
BE & 0.672793 & 0.111907 & 0.095684 & 0.48970 \\
MoGE & 0.648171 & 0.105902 & 0.100006 & 0.432777 \\
EW & 0.663042 & 0.11002 & 0.0987571 & 0.448846 \\
MW & 0.797027 & 0.136277 & 0.10993 & 0.317345 \\
TBX & 0.828701 & 0.141499 & 0.117892 & 0.241425 \\
\hline
\end{tabular}

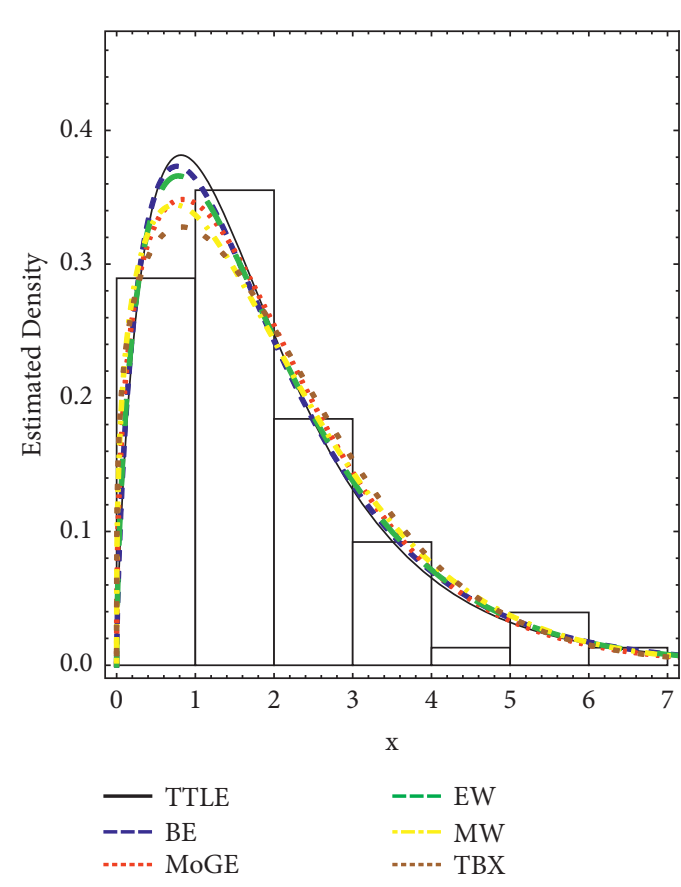

(a)

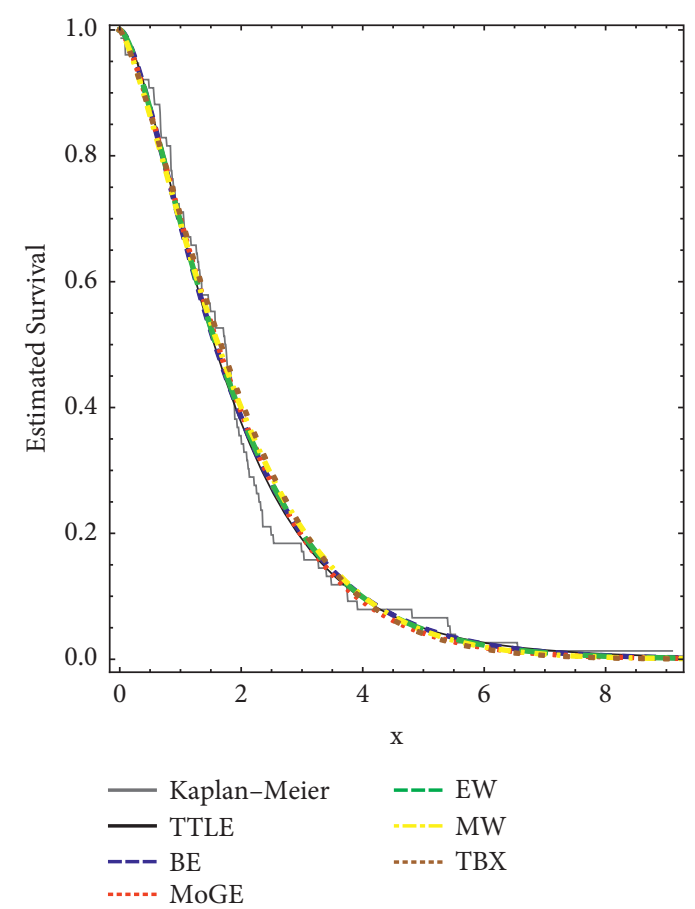

(b)

Figure 11: (a) The estimated density and (b) estimated survival for the Kevlar data.

Table 3 exhibits the MLLEs of the distribution parameters and associated standard errors (StEr) for the current proposal model as well as the challenging distributions for the Guinea Pig data. Likewise, we contrasted the fits of the TTLE model to those of the other models listed in Table 4, including the AINC, BINC, and HQINC. Furthermore, the AND, CVM, and A1 statistics, as well as the equivalent A2, are provided in Table 5. Figures 9 and 10 depict the estimated pdf, estimated sf, and Q-Q plots of the fitted models using Guinea Pig data. These tables and figures show that the suggested model outperforms all competitive distributions in terms of fit. As a consequence, the TTLE distribution may be ranked as the top data fitting model.

For the Kevlar data, the MLLEs for the fitted models and their StErs are computed in Table 6. The goodness-offit measures: AINC, BINC, and HQINC are listed in Table 7. Furthermore, the values of these statistics AND, CVM, A1, and A2 are given in Table 8. Additionally, the plots of estimated density and estimated survival and the 

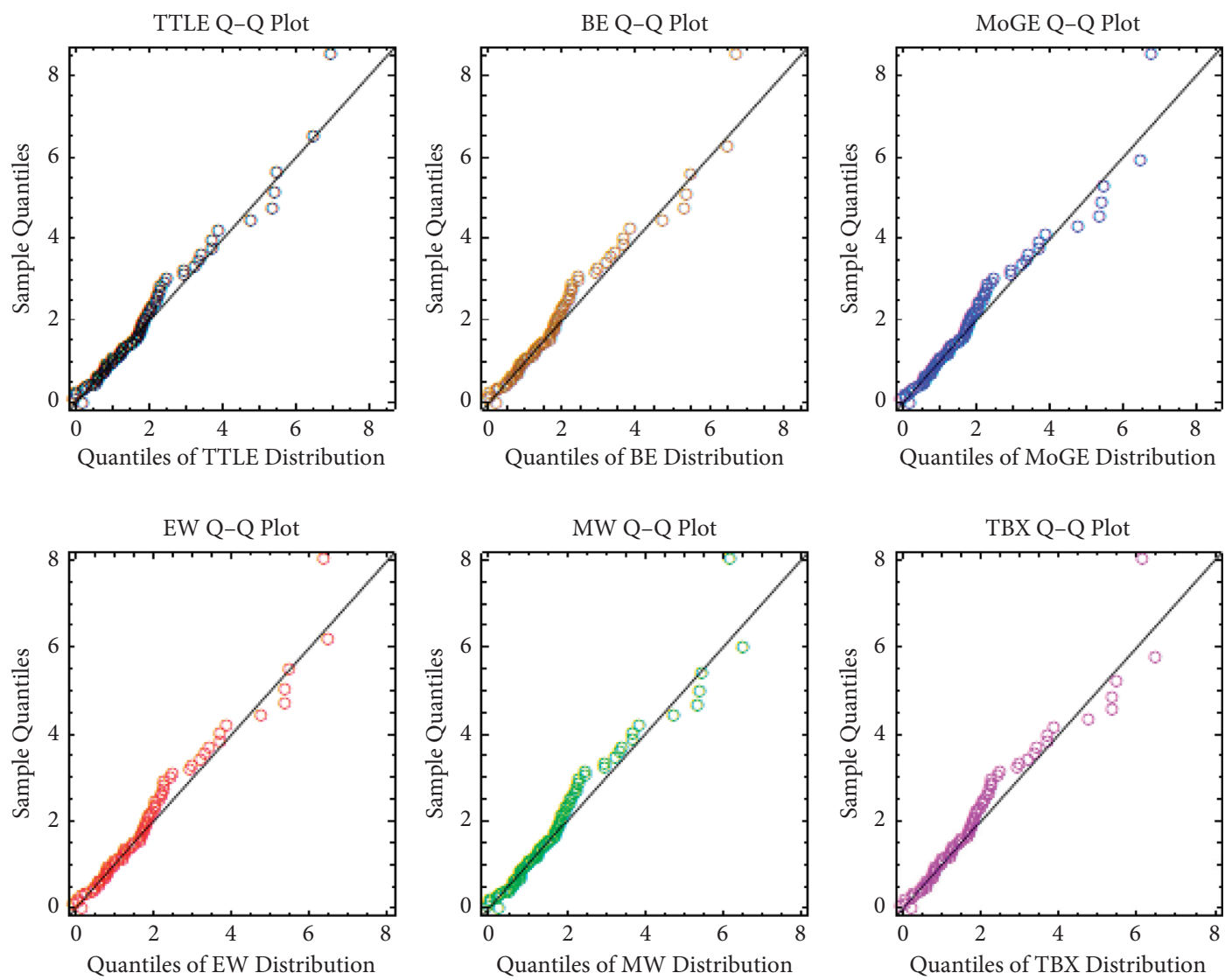

Figure 12: The Q-Q plot of the fitted distributions for the Kevlar data.

Q-Q plot are displayed in Figures 11 and 12. It is evident from Tables 7 and 8 that the TTLE distribution has the weakest goodness-of-fit indices; therefore, this model can be chosen as the better one in fitting this kind of data. In addition, it is clear from Figures 11 and 12 that the TTLE model fits the two real-world data superior than the other competing models.

\section{Conclusion}

This work proposes and explores a new lifetime distribution, the TTLE, to enhance the $E$ distribution. This model's hr function may take the shape of an upside-down bathtub (unimodal), and the constant and diminishing diversity of shapes make the model very adaptable. The suggested model's statistical characteristics and major reliability indicators are deduced. The MLL technique is used to estimate the parameters of the TTLE model. In addition, a numerical result is employed to look into the quality of the estimates. Eventually, real-world data applications are utilized to demonstrate the practicality of TTLE distribution. Also, in the future works, we plan to use this suggested model to study the statistical inference of it using Bayesian estimation under different censored schemes. In the future, other authors can use this model to study its statistical inference using Bayesian and E-Bayesian estimations under complete and different censored schemes.

\section{Abbreviations}

E: $\quad$ Exponential

TTL-G: Transmuted Topp-Leone- $G$

QuF: Quantile function

Mos: Moments

InMos: Incomplete moments

CMos: Conditional moments

MREL: The mean residual life

MINT: The mean inactivity time

EN: Entropy

MLL: Maximum likelihood

BE: The beta exponential

MOGE: Marshall-Olkin generalized exponential

EW: $\quad$ Exponentiated Weibull

MW: The modified Weibull

TBX: Transmuted Burr type $X$.

\section{Data Availability}

To get the numerical dataset used to conduct the study reported in the publication, please contact the corresponding author.

\section{Conflicts of Interest}

The authors state that they have no conflicts of interest to disclose in relation to this work. 


\section{Acknowledgments}

This work was supported by Digiteknologian TKI-ymparisto project A74338 (ERDF, Regional Council of Pohjois-Savo).

\section{References}

[1] W. T. Shaw and I. R. Buckley, "The alchemy of probability distributions: beyond gram-Charlier and Cornish-Fisher expansions, and skew-normal or kurtotic-normal distributions," Submitted, vol. 7, no. 2, p. 64, 2007.

[2] M. H. Tahir, G. M. Cordeiro, A. Alzaatreh, M. Mansoor, and M. Zubair, "The logistic-X family of distributions and its applications," Communications in Statistics - Theory and Methods, vol. 45, no. 24, pp. 7326-7349, 2016.

[3] A. Al-Shomrani, O. Arif, A. Shawky, S. Hanif, and M. Q. Shahbaz, "Topp-leone family of distributions: some properties and application," Pakistan Journal of Statistics and Operation Research, vol. 12, no. 3, pp. 443-451, 2016.

[4] A. S. Hassan, M. Elgarhy, and M. Shakil, "Type II half logistic family of distributions with Applications," Pakistan Journal of Statistics and Operation Research, vol. 13, no. 2, pp. 245-264, 2017.

[5] M. Alizadeh, G. M. Cordeiro, A. D. C. Nascimento, M. D. C. S. Lima, and E. M. M. Ortega, "Odd-Burr generalized family of distributions with some applications," Journal of Statistical Computation and Simulation, vol. 87, no. 2, pp. 367-389, 2017.

[6] H. M. Yousof, A. Z. Afify, M. Alizadeh, N. S. Butt, G. G. Hamedani, and M. M. Ali, "The transmuted exponentiated generalized-G family of distributions," Pakistan Journal of Statistics and Operation Research, vol. 11, no. 4, pp. 441-464, 2015.

[7] H. Reyad, M. Alizadeh, F. Jamal, and S. Othman, "The Topp Leone odd Lindley-G family of distributions: properties and applications," Journal of Statistics and Management Systems, vol. 21, no. 7, pp. 1273-1297, 2018.

[8] M. A. Haq and M. Elgarhy, "The odd Frechet-G family of probability distributions," Journal of Statistics Applications and Probability, vol. 7, pp. 185-201, 2018.

[9] R. A. R. Bantan, F. Jamal, C. Chesneau, and M. Elgarhy, "Truncated inverted Kumaraswamy generated family of distributions with applications," Entropy, vol. 21, no. 11, Article ID 1089, 2019.

[10] M. A. Aldahlan, J. Farrukh, C. Chesneau, M. Elgarhy, and I. Elbatal, "The truncated Cauchy power family of distributions with inference and applications," Entropy, vol. 22346 pages, 2020.

[11] H. M. Yousof, M. Alizadeh, S. M. A. Jahanshahiand, T. G. Ramires, I. Ghosh, and G. G. Hamedani, "The transmuted Topp-Leone G family of distributions: theory, characterizations and applications," Journal of Data Science, vol. 15, no. 4, pp. 723-740, 2017.

[12] M. A. D. Aldahlan and A. Z. Afify, "The odd exponentiated half-logistic exponential distribution: estimation methods and application to engineering data," Mathematics, vol. 8, no. 10, Article ID 1684, 2020.

[13] M. A. D. Aldahlan and A. Z. Afify, "A new three-parameter exponential distribution with appli-cations in reliability and engineering," The Journal of Nonlinear Science and Applications, vol. 13, no. 5, pp. 258-269, 2020.

[14] M. Ibrahim and H. Yousof, "Transmuted Topp-Leone Weibull lifetime distribution: statistical properties and different method of estimation," Pakistan Journal of Statistics and Operation Research, vol. 16, pp. 501-515, 2020.

[15] J. F. Kenney and E. S. Keeping, Mathematics of Statistics, Pt. 1, pp. 100-101, D. Van Nostrand, Princeton, NJ, USA, 3rd ed. edition, 1962.

[16] J. J. A. Moors, "A quantile alternative for kurtosis," The Statistician, vol. 37, no. 1, pp. 25-32, 1988.

[17] T. Bjerkedal, "Acquisition of resistance in Guinea Pigs infected with different doses of virulent tubercle Bacilli1," American Journal of Epidemiology, vol. 72, no. 1, pp. 130-148, 1960.

[18] R. E. Barlow, R. H. Toland, and T. Freeman, "A Bayesian analysis of stress-rupture life of kevlar 49/epoxy spherical pressure vessels," in Proceedings of the Canadian Conference of Applied Statistics, Marcel Dekker, New York, NY, USA, May 1984.

[19] S. Nadarajah and S. Kotz, "The beta exponential distribution," Reliability Engineering and System Safety, vol. 91, no. 6, pp. 689-697, 2006.

[20] M. M. Ristić and D. Kundu, "Marshall-Olkin generalized exponential distribution," Metron, vol. 73, no. 3, pp. 317-333, 2015.

[21] G. S. Mudholkar and D. K. Srivastava, "Exponentiated Weibull family for analyzing bathtub failure-rate data," IEEE Transactions on Reliability, vol. 42, no. 2, pp. 299-302, 1993.

[22] A. M. Sarhan and M. Zaindin, "Modified Weibull distribution," APPS. Applied Sciences, vol. 11, no. 1, pp. 123-136, 2009.

[23] M. S. Khan, R. King, and I. L. Hudson, "Transmuted Burr type $\mathrm{X}$ distribution with covariates regression modeling to analyze reliability data," American Journal of Mathematical and Management Sciences, vol. 39, no. 2, pp. 99-121, 2020.

[24] M. V. Aarset, "How to identify a bathtub hazard rate," IEEE Transactions on Reliability, vol. 36, no. 1, pp. 106-108, 1987. 